University of Nebraska - Lincoln

DigitalCommons@University of Nebraska - Lincoln

May 1990

\title{
SELECTIVE AREA DEPOSITION OF CONDUCTING PALLADIUM FILMS ON POLYIMIDE RESINS
}

\author{
Yoon-Gi Kim \\ Syracuse University \\ S. Bialy \\ Syracuse University \\ R.W. Miller \\ Syracuse University \\ J.T. Spencer \\ Syracuse University \\ Peter A. Dowben \\ University of Nebraska-Lincoln, pdowben@unl.edu \\ See next page for additional authors
}

Follow this and additional works at: https://digitalcommons.unl.edu/physicsdowben

Part of the Physics Commons

Kim, Yoon-Gi; Bialy, S.; Miller, R.W.; Spencer, J.T.; Dowben, Peter A.; and Datta, Saswati, "SELECTIVE AREA DEPOSITION OF CONDUCTING PALLADIUM FILMS ON POLYIMIDE RESINS" (1990). Peter Dowben Publications. 150.

https://digitalcommons.unl.edu/physicsdowben/150

This Article is brought to you for free and open access by the Research Papers in Physics and Astronomy at DigitalCommons@University of Nebraska - Lincoln. It has been accepted for inclusion in Peter Dowben Publications by an authorized administrator of DigitalCommons@University of Nebraska - Lincoln. 


\section{Authors}

Yoon-Gi Kim, S. Bialy, R.W. Miller, J.T. Spencer, Peter A. Dowben, and Saswati Datta 
YOON-GI KIM*, S. BIALY*, R.W. MILLER*, J.T. SPENCER*, P.A. DOWBEN* AND SASWATI DATTA**

*Center for Molecular Electronics, Departments of Physics and Chemistry, Syracuse University, Syracuse, NY 13244-1130

**International Business Machines, 1701 North Street, Endicott, NY 13760

\section{ABSTRACT}

We have demonstrated that the selective area deposition of palladium on polyimide substrates is possible through the U.V. photolys is of $(\pi-a l l y 1)(\pi$-cyclopentadienyl) palladium. This photolytic deposition process did not result in any apparent damage to either the UItem 1000 (polyetherimide) or Kapton substrates (polyimide substrates). The resistivity of the palladium films $(<0.1$ um) suggests that the films are porous.

\section{INTRODUCTION}

Recently, attempts to deposit palladium on polyimide films have used organometallic complexes such as palladium acetate $[1,2]$ with the goal of selectively depositing conducting films through the photolytic decomposition of the complex. Several studies of organometallic source compounds, including $(\pi-a 11 y 1)(\pi$-cyclopentadienyl) palladium, suggest that these complexes can be used to deposit relatively pure palladium films $[3,4]$. These studies have shown that the U.V. photolysis of $\left[\left(\eta^{3}-\mathrm{C}_{3} \mathrm{H}_{5}\right)\left(\eta^{5}-\mathrm{C}_{5} \mathrm{H}_{5}\right) \mathrm{Pd}\right]$ can be used to selectively deposit palladium with submicron spatial resolution [5]. In this paper, we describe the U.V. photolysis of $\left[\left(\eta^{3}-\mathrm{C}_{3} \mathrm{H}_{5}\right)\left(\eta^{5}-\mathrm{C}_{5} \mathrm{H}_{5}\right) \mathrm{Pd}\right]$ on polyimide substrates.

\section{EXPERIMENTAL}

The $(\pi-a 11 y 1)(\pi-c y c l o p e n t a d i e n y l)$ palladium was synthesized and purified using the procedure described previously by Shriver [6]. The photolytic deposition was carried out in a glass vacuum system as described previousiy [7]. The ultraviolet light was a commercially available nitrogen laser (Molectron, model UV 24) with a wavelength of $337 \mathrm{~nm}$. The maximum energy per pulse delivered by this laser was $15 \mathrm{~mJ}$, with a flux density of no greater than $1 \mathrm{~J} / \mathrm{cm}^{2}$. The film thicknesses were estimated from the palladium XES (EDAX), WDS signals and a film thickness monitor (a Taylor-Hobson Talysurf 4). The film thicknesses determined from XES and WDS 
followed from good correlations between the data to model scattering calculations. The film morphology was characterized by scanning electron microscopy (SEM). The purity of the films were determined using a wavelength dispersion spectroscopic (WDS) analysis and Auger electron spectroscopy (AES). Sheet resistance measurements were also undertaken.

The polyimide substrates were exposed to a vapor of [ $\left.\left(\eta^{3}-C_{3} \mathrm{H}_{5}\right)\left(\eta^{5}-\mathrm{C}_{5} \mathrm{H}_{5}\right) \mathrm{Pd}\right]$ for between 17 and 19 hours while irradiating the substrate with the laser beam.

\section{RESULTS}

We have shown that palladium can be deposited on polyimide and the resulting conductive strips are shown in figure 1 .
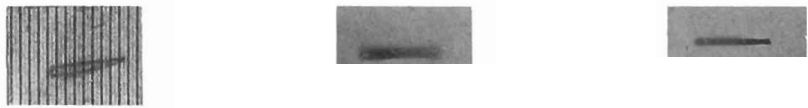

Figure 1 - Palladium films on different polyimide substrates Pd on Kapton (1eft), Pd on Ultem 1000 (rough side) (middle), and Pd on Uitem 1000 (smooth side) (right).

Scratches through the films on Kapton and UItem 1000 did not reveal the presence of any obvious damage to the polyimide films and, in general, the palladium films were found to adhere well to the substrates.

The conducting strips were deposited so that the film thickness was varied along the strip (approximately $500 \AA$ thick at one end but with a decreasing thickness along the length of the strip). We deposited these wedge shaped strips across previously deposited copper lines spaced equally approximately $980 \mu \mathrm{m}$ apart on Kapton. Using this procedure we were able to determine the approximate volume resistance of palladium films for a variety of thicknesses, as shown in figure 2 . 


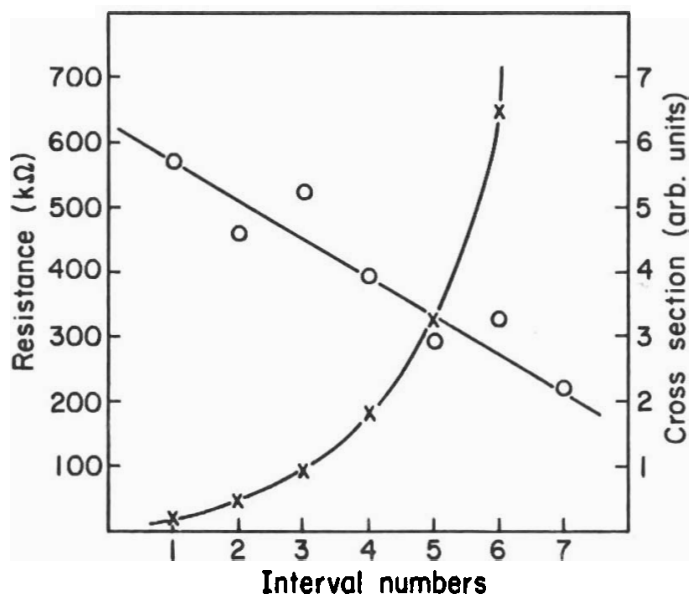

Figure 2 - Resistance (0) and cross $\rightarrow$ sectional area $(x)$ as a function of interva] numbers.

By replotting the data against the palladium strip cross sectional area, it is apparent that the volume resistivity and the conductance of the palladium $\mathrm{film}$ is dependent on the film thickness. This is shown in figure 3.

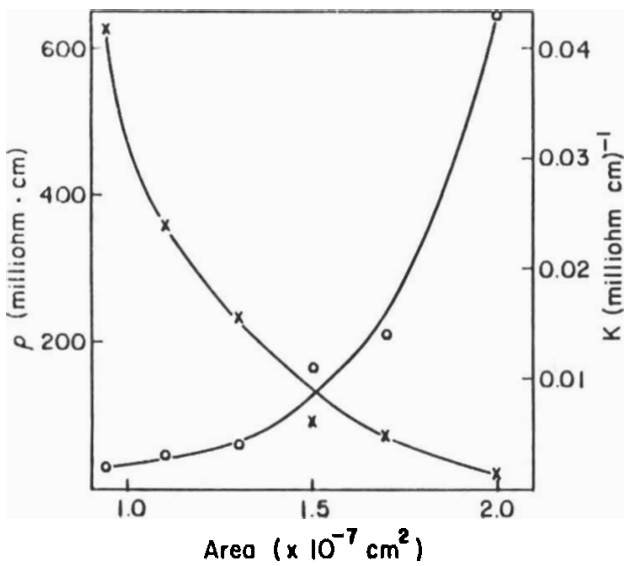

Figure 3 - Volume resistivity $(x)$ and Conductivity (o) as a function of area. 
While substantial errors in the estimates of the film thickness are possible, the relative thicknesses cannot be in error by more than $15 \%$. It can thus be surmised that the resistivity is strongly dependent upon film thickness. With a thickness of approximately $500 \AA$, the wire on the Kapton has a resistivity between $2.3 \times 10^{-2} \mathrm{ohm}-\mathrm{cm}$ and $62.3 \times 10^{-2} \mathrm{ohm}-\mathrm{cm}$. This is significantly greater than the resistivity of pure palladium $\left(1.08 \times 10^{-5}\right.$ ohm-cm). From figure 3 , it is apparent that the volume resistance increases monotonically as the palladium cross-section decreases. It can be inferred from this result that for films of thickness less than $500 \AA$, the films are very porous. For uniform films, one expects no variation in the volume resistivity. With a film thickness of $150 \mathrm{~A}$, the resistivity of the palladium film on the Ultem 1000 is $7.8 \times 10^{-2} \mathrm{ohm}-\mathrm{cm}$. Palladium films on the Ultem 1000 are therefore also very porous, but less so, than for the films on Kapton.

Porous films have also been observed in platinum films deposited by the U.V. photolytic decomposition of $\left[\left(\eta^{3}-C_{3} \mathrm{H}_{5}\right)\left(\eta^{5}-\mathrm{C}_{5} \mathrm{H}_{5}\right) \mathrm{Pd}\right]$ [8]. These films were observed, however, to contain substantial amounts of carbon. Porous films can result from rapid deposition at catalytically active sites. The rapid growth of films at catalytically active nucleation sites has been observed previously and can accompany the photolysis of organometallic species [9-12]. We propose that for the deposited palladium on polyimide substrates from $(\pi$-allyl)( $\pi$-cyclopentadienyl) palladium, a nucleation mechanism must be involved, i.e., palladium islands are more catalytically active for photolytic decomposition of $\left[\left(\eta^{3}-\mathrm{C}_{3} \mathrm{H}_{5}\right)\left(\eta^{5}-\mathrm{C}_{5} \mathrm{H}_{5}\right) \mathrm{Pd}\right]$ as the source material.

For thicker palladium films, $(\pi-a] 1 y 1)(\pi$-cyclopentadienyl) palladium [ $\left.\left(\eta^{3}-\mathrm{C}_{3} \mathrm{H}_{5}\right)\left(\eta^{5}-\mathrm{C}_{5} \mathrm{H}_{5}\right) \mathrm{Pd}\right]$, may be a suitable alternative to palladium acetate, since $\left[\left(\eta^{3}-\mathrm{C}_{3} \mathrm{H}_{5}\right)\left(\eta^{5}-\mathrm{C}_{5} \mathrm{H}_{5}\right) \mathrm{Pd}\right]$ is significantly more volatile than palladium acetate. For selective area deposition, deposition from the gas phase may have applications where spin coating does not.

\section{CONCLUSION}

From analysis of our films on polyimide substrates and other $[1,2]$ studies on silicon substrates, we know that the process is photolytic and the films are very pure by more than $99 \%$ by wt\%.

Adhesion of the palladium films to polyimide substrates is very good. The volume resistivity of the very thin palladium films $(<0.1 \mu \mathrm{m})$ on the Kapton and polyimide substrates is significantly greater than for pure palladium. It is proposed that these results show that CVD palladium films can be applied to the fabrication of thin film resistors and interconnects. 


\section{ACKNOWLEDGEMENTS}

This work was funded by I.B.M. (research agreement number 8074), by A.F.O.S.R. (contract number F30602-88-0-0027 administered by RADC as task A91913), and by the National Science Foundation (CHEM-8900471). The authors would like to thank $H$. Cole for his generosity in providing substrate materials.

\section{REFERENCES}

[1] H. Esrom, G. Wah1 and M. Stuke, Mat. Res. Soc. Proc. 131, 581 (1989).

[2] Y.S. Liu and H. Cole, Mat. Res. Soc. Proc., 129, 579 (1989)

[3] G.T. Stauf, P.A. Dowben, K. Emrich, S. Barfuss, W. Hirschwaid and N.M. Boag, J. Phy. Chem., 93, 749 (1989).

[4] K. H. Emrich, G.T. Stauf, W. Hirschwald, S. Barfuss, P.A. Dowben, R.R. Birge and N.M. Boag, Mat. Res. Soc. Proc. 131, 401 (1989).

[5] G.T. Stauf and P.A. Dowben, Thin Solid Films, 156, L31 (1988).

[6] D.F. Shriver ed., Inorganic Synthesis, John Wiley and Sons, vol. 19, p. $221,1979$.

[7] G.T. Stauf, P.A. Dowben, N.M. Boag, L. Morales de 1a Garza and S.L. Dowben, Thin Solid Films, 156, 327 (1987).

[8] D. Rooney, D. Negrotti, T. Byassee, D. Macero, J. Chaiken and B. Vastag, Use of Laser Directed Chemical Vapor Deposition to Fabricated Durable-Optically Transport, Platinum Thin Film Electrodes, J. Electrochemical Soc. (unpublished).

[9] M. Paunovic and C.H. Ting, in Electroless Deposition of Metals and Alloys, edited by M. Paunovic and I. Ohno (Proceeding of the Electrochemical Society, Vol. 88-12, Pennington, NJ 1988).

[10] W. Krauter, D. Bauerle and F. Fimberger, App1. Phys. A $\underline{31}, 13$ (1983).

[11] C. Arnone, M. Rothschild, J.G. Black and D.J. Ehrlich, App1. Phys. Lett., 48(15), 1018 (1986).

[12] H. Yokoyama, F. Uesuqi, S. Kishida and K. Washio, Appl. Phys. A 37, 25 (1985). 